\title{
CONTRIBUIÇÕES DA DISCIPLINA MEMÓRIA E ORGANIZAÇÃO DOS ESPAÇOS PEDAGÓGICOS EM EPT PARA UM PROJETO DE MUSEU INTERATIVO DE MEMÓRIAS
}

\author{
Paula Souza da Silva ${ }^{\mathrm{I}}$
}

RESUMO: O presente artigo aborda conceitos e teorias apreendidos através da disciplina que contribuíram, ao fornecer embasamento teórico, para a proposta de um museu interativo de memórias do Campus Santos Dumont do IF Sudeste. Um museu virtual enquanto espaço de educação não formal pode contribuir com a formação humana integral dos seus visitantes/alunos ao expô-los a atividades coletivo-reflexivas com potencial para torná-los indivíduos mais críticos, emancipados, inovadores e transformadores de si mesmos e da realidade a que pertencem e com a qual passam a se identificar.

Palavras-chave: História e Memória da EPT em Santos Dumont. Espaços não formais e formação integral.

\section{INTRODUÇÃO}

O Campus Santos Dumont do Instituto Federal do Sudeste de Minas Gerais está localizado em um espaço que já sediou outras instituições de educação profissional: 1941 - I943 Escola Profissional de Santos Dumont, 1943-1973 Escola Profissional Fernando Guimarães, 1974 - 2004 Centro de Formação Profissional de Santos Dumont, mantida pela Rede Ferroviária e SENAI, 2004 - 2008 Centro Municipal de Educação Profissional - CEMEP de Santos Dumont e de 2008 até os dias atuais o IF Santos Dumont.

Ainda existe disperso pelo Campus ou em uso nas oficinas/laboratórios ferramentas, equipamentos, documentos acadêmicos e fotos históricas herdadas dessas instituições pelo Campus Santos Dumont.

\footnotetext{
${ }^{1}$ Mestrando em Educação Profissional e Tecnológica pelo Instituto Federal de Educação, Ciência e Tecnologia do Sudeste de Minas Gerais, Brasil. Currículo lattes: http://lattes.cnpq.br/6492494049335916. Email: paula.silva@ifsudestemg.edu.br
} 
A necessidade de preservar e disseminar toda essa história levou a proposta de um museu virtual interativo de memórias como produto educacional do Mestrado profissional em educação profissional e tecnológica do IF SUDESTE MG.. O museu seria, então, o local para exposição virtual de objetos que remetem a memórias e que contam uma parte da história da educação profissional da cidade de Santos Dumont e de inúmeros personagens que fizeram e ainda fazem parte dela, além de ser também um espaço de debate e de produção de conhecimento, e não de simples contemplação, considerando sempre que possível o mundo do trabalho a partir de estudos relacionados ao contexto histórico da Educação Profissional em Santos Dumont.

Trata-se, portanto, de um processo de concepção e organização de um espaço não formal pedagógico na Educação Profissional e Tecnológica, com foco nas estratégias transversais e interdisciplinares, que possibilitem formação integral e significativa do estudante.

Os registros históricos dessa história de educação profissional serão identificados, catalogados e disponibilizados em uma plataforma denominada Museu Interativo de Memórias (MIM), onde tal história poderá ser visitada (CULTURA), estudada e pesquisada (CIÊNCIA) e contribuir a proposta de formação integral humana de profissionais (TRABALHO), enquanto recurso didático (através do ENSINO), fonte de busca e criação de conhecimento (através da PESQUISA), e espaço de cultura e identidade para a comunidade interna e externa (através da EXTENSÃO). Além de contribuir para o fortalecimento da identidade institucional junto à comunidade interna e externa.

Nos tópicos seguintes serão apresentados os autores, conceitos e teorias aprendidos na disciplina MEMÓRIA E ORGANIZAÇÃO DOS ESPAÇOS PEDAGÓGICOS EM EPT que contribuem para a elucidação e embasamento do referido projeto.

\section{História, memória e identidade: 78 anos de EPT na cidade de Santos Dumont}

A disciplina Memórias e organização de espaços pedagógicos em Educação Profissional e Tecnológica apresentou-nos um conceito imprescindível quando nos 
predispomos a recontar uma história a partir dos seus legados: o conceito de memória.

No programa da disciplina MEMÓRIA E ORGANIZAÇÃO DOS ESPAÇOS PEDAGÓGICOS EM EPT encontramos três autores que tratam desse tema Le Goff (2013), Oliveira (2017) e Ricoeur (2007).

Ricoeur (2009) nos fala que a memória é a representação do passado

\begin{abstract}
A permanente ameaça da confusão entre rememoração $e$ imaginação, que resulta desse tornar-se imagem da lembrança, afeta a ambição de fidelidade na qual se assume a função veritativa da memória. [...] E, no entanto, nada temos de melhor que a memória para garantir que algo ocorreu antes de formarmos a sua lembrança. (RICOEUR, 1990, p. 26).
\end{abstract}

A definição de Ricoeur (1990) corrobora com intenção deste projeto que é criar um espaço para lembrar. Faz se necessário ainda duas outras ponderações quando intencionados a entender memória como espaço que reúne lembranças, são elas: memória diferente de história e memória oficial diferente de memória subterrânea, ambas tratadas por autores da bibliografia da disciplina em tela.

A diferença entre memória e história é outra contribuição atribuída a Le Goff (2013) e também Ricouer (1990); ambos nos apresentam a história como crítica da memória, ou seja, a ciência que vai analisar criticamente as lembranças materializadas em memórias.

Le Goff (2013) sobre a relação entre memória e história nos diz:

Tal como o passado não é a história, mas o seu objeto, também a memória não é a história, mas um dos seus objetos e, simultaneamente, um nível elementar de elaboração histórica. (LE GOFF, 2013, p. 5I).

Quando a História se apropria da memória, esta deixa de existir, restando apenas os lugares de memória, o MIM (Museu Interativo de Memórias|) seria, portanto, um lugar de memória.

A discussão com relação à importância de memórias subterrâneas que, como parte integrante das culturas minoritárias e dominadas, se opõem à "Memória oficial" facilmente confundida com memória institucional também foi outra grande contribuição da referida disciplina. 
O MIM por ser apenas um lugar de lembranças não diminuirá ou elevar a importância das suas fontes documentais, mas sim garantir que todas as testemunhas da história sejam ouvidas ou ao menos representadas. Entretanto, essa demanda por uma análise crítica dessas memórias poderia ser sanada através de projetos de pesquisa e extensão pelo núcleo de história do Campus.

Essa preocupação em avaliar a memória como documento histórico, segundo Le Goff (2013) está diretamente relacionada ao seu papel na construção da identidade, outro coneito trazido pela disciplina.

A memória é um elemento constituinte do sentimento de identidade, tanto individual como coletiva.

De acordo com Le Goff (2013)

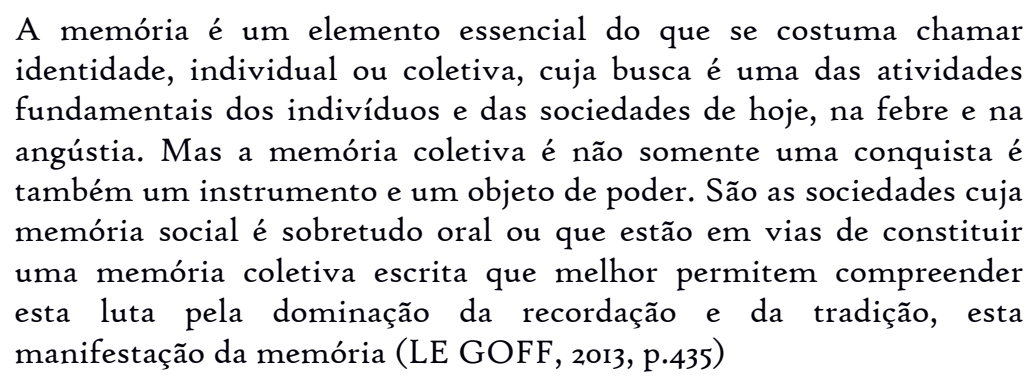

As discussões acima, conteúdos da disciplina Memórias e organização de espaços pedagógicos em Educação Profissional e Tecnológica, nos mostram que é relevante refletir sobre as possibilidades de uma memória institucional do Campus Santos Dumont, visto que as organizações em geral ocupam um espaço importante na sociedade e influência e interfere na vida dos seus colaboradores e todas desejam a identificação dos seus colaboradores

As iniciativas no campo da memória institucional levam a preservação da imagem corporativa, "contribuindo para a perpetuação e é uma maneira bastante contundente de antever o futuro (MARICATO, 2006). Podem servir, ainda, para criar valor para as organizações e a defesa de sua imagem em crises (NASSAR, 2007).

Ciavatta (2005), autora apresentada pela disciplina, no seu artigo “A formação integrada: a escola e o trabalho como lugares de memória e identidade, nos 
fala ainda que a memória institucional é imprescindível também em instituições de educação subsidiando a proposta desse produto educacional.

Para que as escolas sejam capazes de construir organicamente o seu próprio projeto político-pedagógico, assumirem o desafio de uma formação integrada, reafirmando a sua identidade, é preciso que conheçam e compreendam a sua história. Que reconstituam e preservem a sua memória, compreendam o que ocorreu consigo ao longo dos últimos oito anos de reforma e, então, a partir disto, decidir coletivamente para onde se quer ir, como um movimento permanente de autorreconhecimento social e institucional. E, então, reconhecerem-se como sujeitos sociais coletivos com uma história e uma identidade própria a ser respeitada em qualquer processo de mudança. (CIAVATTA, 2005, p. 22)

A formação do acervo do MIM, iniciará com a seleção dos itens que melhor representam o passado que se preservará e a identidade institucional que se fortalecerá e como em todo processo de escolha e de seleção, ou seja, relevante para instituição: “a cultura, os comportamentos, os símbolos, a identidade e a comunicação, o conjunto de elementos que formam a personalidade de uma empresa ou instituição, serão os grandes pilares desse acervo de memória”

\section{Museu Interativo de Memórias como espaço de educação não formal para apoio ao ensino, pesquisa e extensão}

Os museus, portanto, são criados para abrigar os chamados "lugares de memória" para aqueles que tem "vontade de memória".

Entretanto, quando se fala em identificar, organizar, disseminar e utilizar didaticamente as memórias do IF sudeste-Campus Santos Dumont, não podemos pensar em memória apenas como possibilidade de identidade e/pertencimento institucional, mas também como fonte para produção do conhecimento (trabalho, cultura, pesquisa) e para a ressignificação da educação e da cidadania.

A memória não se vincula somente ao conhecimento da própria instituição, mas também dos campos disciplinares nos quais atuam, a chamada etnografia dos saberes escolares.

Nesse sentido, é preciso considerar o papel educativo do museu, enquanto espaços não formais de aprendizagem capazes de contribuir com uma proposta de formação humana integral. 
Os museus são, por excelência, locais de observação, interação e reflexão. Desta forma, os museus podem ser trabalhados como espaço de discussão de idéias, espaço de aprendizagem conseqüente e não somente como o lugar do lúdico ou da contemplação. (SMANIOTTO, 2or6, p.3)

A compreensão de espaços não formais foi mais uma contribuição da disciplina, mas a definição adotada no projeto foi a de MARANDINO (2008)

O termo "espaço não formal" tem sido utilizado atualmente por pesquisadores em Educação, professores de diversas áreas do conhecimento e profissionais que trabalham com divulgação científica para descrever lugares, diferentes da escola, onde é possível desenvolver atividades educativas.(MARANDINO, 2008, p.55)

Segundo Nunes (2003) o uso pedagógico dos espaços de memória possibilita um discurso genuinamente libertador, principalmente ao incentivar que o sujeito se identifique e, dessa forma, envolvendo-se com a sua realidade, responsabilizando-se por transformá-la.

Nunes (2003, p. 35) pergunta

Porque não utilizá-los (memória escolar) nas atividades curriculares aí desenvolvidas? Quando as escolas começam a organizar a sua memória em torno de pequenos museus escolares, ou exposições, os arquivos costumam emprestar os seus documentos e apenas nessas ocasiões eles são solicitados, mas, porque não trabalhar os dossiês dos estudantes, os álbuns fotográficos, os jornais ali produzidos como material para provocar a aprendizagem de disciplinas como a História, a Geografia? (NUNES, 2003, p. 35)

Faz-se necessário perguntar ainda, uma vez hospedada em um museu a memória institucional e escolar do Campus Santos Dumont e atendida a sugestão/citação de Nunes (2003) de utilizar tal acervo nas atividades curriculares, como garantir que tal ação contribua para a formação humana integral, outro conceito amplamente discutido na disciplina, principalmente em Brasil(2007).

Os institutos federais são instituições de ensino criadas para oferecer formação profissional integralmente. A formação integral defende que a formação profissional deve estar atrelada ao desenvolvimento do ser humano, como ser onmilateral, ser social, ser espiritual, ser político, ser que trabalha, pensa e produz cultura.

Daí o grande desafio dos Institutos Federais, tão discutido em sala de aula; segundo MEC (2012): 
Trilhar um novo caminho da educação profissional no Brasil, alicerçada no desenvolvimento do ser humano, como ser integral e integrado com o mundo que o rodeia; ser que trabalha, que produz conhecimento e cultura. (MEC, 2012, p. 27)

Uma vez ciente da obrigação dos Institutos Federais em buscar a formação humana integral nos seus cursos cresce as expectativas por projetos que demonstrem essa integração CIÊNCIA, TRABALHO E CULTURA, de preferência dialogando com a comunidade; um museu virtual interativo de memórias pretende ser uma dessas propostas.

\begin{abstract}
Para que as escolas sejam capazes de construir organicamente seu próprio projeto político-pedagógico, assumirem o desafio de uma formação integrada, reafirmando a sua identidade, é preciso que conheçam e compreendam a sua história. Que reconstituam e preservem a sua memória, compreendam o que ocorreu consigo ao longo dos últimos anos e, então, a partir disto, decidir coletivamente para onde se quer ir, como um movimento permanente de autorreconhecimento social e institucional. E, então, reconheceremse como sujeitos sociais coletivos com uma história e uma identidade própria a ser respeitada em qualquer processo de mudança. (CIAVATTA, 2005, p.3I)
\end{abstract}

Acredita-se que o MIM, pode auxiliar a escola a reafirmar a sua identidade

e será uma forma de apresentar ao discente o mundo nos diversos aspectos que fazem parte da vida social, que segundo JESUS (2018), é condição necessária para a formação integral.

Além da visitação ao acervo virtual, da personalização das visitas e do oferecimento de atividades interativas para entretenimento e conhecimento do acervo, haverá no MIM um espaço destinado à aprendizagem, esse espaço chamado “ uma aula no museu”, será manipulado por professores para que estes possam utilizar o acervo e algumas ferramentas de apoio para ensinarem os seus conteúdos. Enquanto o aluno aprende o conteúdo curricular ele conhece e se identifica com a história da educação profissional na sua cidade, com a história da sua comunidade e com a sua própria história tomando consciência da sua capacidade para transformálos.

Objetiva-se com um museu virtual interativo de memórias criar espaços educativos, voltados para dinamizar os conhecimentos; e promover situações de aprendizagem voltadas para o desenvolvimento da autonomia e da capacidade de 
liderança do aluno ao navegar pelas obras utilizando os periféricos de interface e tirar delas informações relevantes para a sua construção de conceitos e valores ao mesmo tempo em que socializa com a memória da sua escola e da sua comunidade.

Pensar, discutir e fazer uso dessas memórias nas salas de aula ou laboratórios dos Institutos Federais é garantir um diálogo estreito entre a comunidade e a escola, entre o indivíduo e a coletividade e entre a ciência, o trabalho e a cultura, contribuindo para formação integral e política dos alunos.

\section{CONSIDERAÇÕES FINAIS}

A disciplina Memórias e organização de espaços pedagógicos em Educação Profissional e Tecnológica contribuiu para o amadurecimento desse projeto ao fornecer-lhe uma estrutura conceitual e teórica legitimadora.

Todos esses conceitos (memória, identidade, espaços não formais, formação integrada e integral) estavam soltos e dispersos como o acervo do futuro museu virtual. A necessidade de organização documental era clara, mas não a sua contribuição para a Instituição e principalmente para um mestrado em ensino.

Os conceitos de memória e identidade, e a relação entre eles e a História eram essenciais para a base do projeto e a disciplina contribuiu apresentando autores que falam do tema com maestria e clareza. Le Goff (2013), Oliveira (2017) e Ricoeur (2007) foram exaustivamente referenciados na introdução do projeto ao tentar demonstrar o potencial cultural, científico, institucional e didático de até então "um monte de coisas antigas”.

Essas coisas antigas agora são chamadas de memórias. A possibilidade de elas criarem na comunidade interna e externa sentimentos de pertencimento a instituição, agora sabemos, tem a ver com Identidade. Todo esse material ao ser usado em prol da aprendizagem de conteúdos da escolarização formal em um museu, mesmo que virtual, é formação em espaço não formal.

O potencial desses espaços não formais para uma formação humana integral era tão difícil de defender e de demonstrar até que indiretamente a disciplina nos apresentou JESUS (2018) e todas as suas referências.

Até essa disciplina, a expectativa era somente a de disponibilizar uma 
memória institucional para a comunidade interna e externa do Campus Santos Dumont de modo a fortalecer a identidade institucional e criar valores organizacionais (pertencimento, envolvimento, motivação).

Entretanto, isso seria muito pouco para uma Instituição com um propósito tão árduo e tão significativo e também para um mestrado em ensino.

Chegou a se pensar também na possibilidade de integralização curricular utilizando o acervo histórico e mais uma vez essa disciplina contribuiu ao clarear o conceito de integralização curricular e diferenciá-lo de interdisciplinaridade. Era realmente impossível integralizar disciplinas básicas e tecnológicas a partir de um acervo histórico em um museu virtual.

Então vieram as discussões sobre os espaços não formais e suas características aliadas da formação humana integral. $\mathrm{O}$ museu virtual assim como todo espaço não formal de aprendizagem é propicio para a autonomia, para a emancipação, para a crítica, para a reflexão. E quando este espaço permite o acesso à história da educação, do trabalho e do entorno ele está permitindo também o acesso as histórias individuais, da coletividade, da instituição e despertando o desejo de se identificar com as mesmas e transformá-las.

Poderia se resumir assim: a disciplina clareou idéias, apontou caminhos, deu nome a conceitos e autores essenciais para tornar o objetivo desse projeto mais claro, coerente e aplicável e incentivou a organização da memória de uma instituição de ensino e a utilização da mesma em um espaço pedagógico em EPT não formal.

\section{REFERENCIAS}

\section{UTILIZADAS NO PROGRAMA DA DISCIPLINA E NO PROJETO/ARTIGO}

BRASIL. Ministério da Educação Secretaria de Educação Profissional e Tecnológica. Educação profissional técnica de nível médio integrada ao ensino médio:documento base. Brasília, dezembro de 2007

BURKE, P., O que é História Cultural? Trad. Sergio Goes de Paula $2^{\underline{a}}$ ed. Rio de Janeiro: Jorge Zahar Editora. 2008.

CHARTIER, R.. A História Cultural: entre práticas e representações. Lisboa: DIFEL, I990. 
CIAVATTA, M.. O trabalho docente e os caminhos do conhecimento: a historicidade da Educação Profissional. Rio de Janeiro: Lamparina, 2015.

FRIGOTTO, G.; CiAVATTA, M.; RAMOS, M. (Org). Ensino Médio Integrado: concepção e contradição. São Paulo: Cortez, 2002.

LE GOFF, J. História e memória. Tradução de Bernardo Leitão [et al.]. Campinas: Editora da UNICAMP, 2013.

LE GOFF, J.. Documento/Monumento. In LE GOFF, Jacques. História e Memória. 4.ed. Campinas:Unicamp, 1996.

OLIVEIRA, J.R..; RAMOS, T.O.; FARTES, V.L.B. Memórias, Educação e Produção do Conhecimento no Instituto Federal da Bahia. Salvador, Bahia(IFBA): Edifba, 2017.

RICOEUR, P.. A memória, a história, o esquecimento. Campinas: Editora UNICAMP, 2007.

\section{UTILIZADAS NO PROJETO/ARTIGO RELACIONADAS A DISCIPLINA}

CIAVATTA, Maria. A formação integrada: a escola e o trabalho como lugares de memória e de identidade. Trabalho Necessário. Ano 3, N. 3, 2005.

JESUS, C. S. Reflexões sobre técnica e espaço na educação não-formal. . Synesis, v. Io, n. 2, p. 168-180, ago/dez 2018.

MARANDINO, M. (Org.). Educação em museus: a mediação em foco. São Paulo: Grupo de Estudo e Pesquisa em Educação Não-formal e Divulgação em Ciências, 2008. Disponível em. Acesso em: mar. 2017.

MARICATO, Adriano. História e memória. In MARCHIORI, Marlene (org). Faces da cultura e da comunicação organizacional. São Caetano do Sul, SP: Difusão Editora, 2006.

NASSAR, Paulo(org). Memória de empresa: história e comunicação de mãos dadas, a construir o futuro. São Paulo: Aberje, 2004.

NUNES, C.. Memória e História da Educação: entre práticas e representações. In: Maria Cristina Leal; Marília Pimentel. (Org.). História e Memória da Escola Nova..Rio de Janeiro: Loyola, 2003, v. I, p. 9-26

SMANIOTTO, E. Museu: um espaço de aprendizagem: sobre mudanças Tecnológicas ocorridas durante o século XX. Disponível em: < https://www2.faccat.br/portal/sites/ default/files/MUSEU\%20\%20UM\%20ESPACO\%2oDE\%20APRENDIZAGEM.pdf> Acesso em: 17 jul. 2017. 